\title{
A Study on the Social Governance Function of Cultural Industry of the Directly-entering-socialism Ethnic Group Areas \\ -A Case Study of Lao Dabao Happy Lahu Performing Arts Company of Lancang County
}

\author{
Yan Xiong* \\ School of Public Management \\ Yunnan University of Finance and Economics \\ Kunming,China \\ (yxiongemail@163.com)
}

\author{
Yue Yijing \\ School of Public Management \\ Yunnan University of Finance and Economics \\ Kunming,China \\ (632931370@qq.com)
}

\begin{abstract}
The development of cultural industry in the directly-entering-socialism ethnic group areas with backward economy and rich cultural resources can exert five social governance functions such as serving as the "catalyst" to help cast off poverty and get rich. The paper focuses on Lao Dabao Happy Lahu Performing Arts Company of Yunnan Lancang County to find out the obstacles of the cultural industry of Yunnan directly-entering-socialism ethnic groups in exhibiting social governance functions, which is of great practical significance for the Party and government to improve the social governance of the directly-entering-socialism ethnic groups.
\end{abstract}

Keywords-directly-entering-socialism ethnic groups; cultural industry; social governance; Lao Dabao

\section{INTRODUCTION}

\section{A. Significance of the Study}

Cultural industry, as a new form of economics, is both endowed with the economic nature of the general industry and the political nature characterized by Supreme of National Benefits as well as the social nature of highlighting social benefits. Its comprehensive social governance potential is especially embodied in the directly-entering-socialism ethnic group areas: due to different living conditions, there has appeared the traditional culture of directly-entering-socialism ethnic groups in various forms and substances, which still maintains the old-fashioned ideology with a backward economy and low living standards. Thus, it is of vital importance for the Party and government to improve the living conditions of directly-entering-socialism ethnic group areas, to strengthen and innovate the social governance of such areas to maintain the harmony and stability of the 56 ethnic groups in our country.

To develop the cultural industry in directly-enteringsocialism ethnic group areas is to serve as the "catalyst" to help cast off poverty and get rich, as the "loader" to carry forward culture, as the "lubricant" to improve the relationship between cadres and masses, as the "stabilizer" to maintain the national unity and as the "pusher" to promote social stability and progress. The paper focuses on the Lao Dabao Happy Lahu Performing Arts Company of Yunnan Lancang County (representative of Lahu cultural industry) to study obstacles of the cultural industry of Yunnan directly-entering-socialism ethnic groups in exhibiting social governance functions, which is of great practical significance for the Party and government to improve the social governance of the directly-enteringsocialism ethnic groups.

\section{B. Literature Review}

In the 1960s, the Birmingham School combined cultural forms with social structures into the analyzing thought of "sociology about culture." With the emergence of the global cultural development strategy, the government begins to apply the cultural strategy to the selective constraint and guidance of public and private behaviors in society about cultural development. In 1996, the UN World Commission on Culture and Development issued the report Our Creative Diversity to extend the concept of governance to the discussion of cultural development. $^{2}$

The earliest social governance function in the Chinese history can date back to the time when "the ancient kept records and ruled by tying knots, while the later generations referred to written agreements instead." The ancient working people created culture and kept records by tying knots to rule the country. ${ }^{3}$ Since the founding of new China, a great many scholars have been focusing on such areas as social and cultural constructions with a further analysis of the relevant institution, mechanism, strategy and historical dimensions. Since the 21st century, China has equated socialist cultural development with political, economic, and social development, during which the governance issues are addressed with relevant policies made and implemented. 
Li Changchun pointed out in Speech at the Forum on the pilot Reforms of the Cultural System that culture is the fundamental force of national survival and development. ${ }^{4}$ In 2012, Hu Huilin put forward the concept of national cultural governance, holding that cultural industry may be governed in concern with politics, economics, culture and society. The hot issue of cultural development strategy also reflects the more and more important position and function of cultural industry in society. Professor Zhu Lijia proposed the concept of "cultural industry governance," holding that culture is a spontaneously emerging belief, and the concept of "governance" entails "control," so "cultural governance" should be carefully handled, which provides a more precise perspective for later scholars to study the function of cultural governance..$^{5}$

Therefore, in the historic process of human society, culture is the exclusive choice to resolve conflicts between man and man, man and society, man and nature, indicating that the social governance function of culture is widely accepted and thus focused on from different angles by scholars both at home and abroad. In summary, the paper holds that the social governance of cultural industry is a function that multiple social subjects exploit the characteristics of cultural industry to address issues in various aspects of social system for the purpose of good governance.

\section{Background Introduction}

Directly-entering-socialism ethnic groups, a special term under the special historical conditions, refer to the Lahu, Jingpo, Blang, Va ethnic groups in Yunnan province which transitioned directly from primitive society over several social historical forms to socialist society with a population of over 600, 000. ${ }^{6}$

Lancang County, one of the national poverty counties, is also the origin of Lahu in the world and the homeland of Lusheng love songs. Lao Dabao village group belongs to Menggeng village committee of Jiujing Hani Township of Lancang County. As one of the Lahu cultural inheritance bases, it is a typical village of directly-entering-socialism ethnic groups with 114 households and 473 villagers. The villagers still live in traditional Lahu railed buildings. The development basis, mode and environment of the village still remain different from the inland areas with its own distinctiveness. ${ }^{7}$

With the development of peasant art groups, the first Performing Arts Co. Ltd in Pu'er City was established by peasants themselves in 2013 in Lao Dabao of Jiujing Township of Lancang County -- Lao Dabao Happy Lahu Performing Arts Company of Lancang County (Hereinafter referred to as Lao Dabao Company). The real-life-scenery customs performance the company presents is well received by the tourists and media. Lao Dabao Village is recognized as the demonstration village of special cultural property to guide the villagers either to work in the fields with hoes on their shoulders, or perform on the stage with shining boots on their feet instead of the traditional life of working from dawn to dusk. The villagers get richer and happier.

\section{The Current Situation OF LaO DaBao COMPANY}

Qualitative leaps have been made in Lancang County's cultural industry since the establishment of Lao Dabao Company, which materially and spiritually, fully indicates the necessity of bringing into play the social governing function by emphasizing the importance of cultural industry. By means of benefiting and enriching the people, it aims at attracting people. Specifically speaking, the current situation of Lao Dabao cultural industry presents itself in the following five aspects.

\section{A. Catalyst of Prosperous}

Taking advantage of Lahu culture, Lao Dabao Company finds new way to increase farmers' income. In 2012, the per capita net income was only 2,030 yuan; however, since the establishment of the company, 140 performances have been delivered which brings with them an income of nearly 1.3 million yuan. The local people have received dividends of 600,000 yuan. What is more, it improves the income of other surrounding industries about 900,000 yuan. In 2013, it won the honorary title of "Rural Cultural Industry Advanced Model" of Yunnan province and the per capita net income was 2,253, with a year-on-year growth of $10.98 \%$; however, the gross income of Lao Dabao villager group in 2014 reached 2.36 million yuan and per capita income was 2,573 yuan, with a year-on-year growth of $14.2 \%$. During the Spring Festival of this year, from the third day to seventh, the income of the company was more than 110,000 yuan. Furthermore, Lao Dabao, possessing a promise future, is made central part of HALEJA country music town which is invested by municipal party committee and municipal government of 530 million yuan. By changing national cultural advantage into industrial advantage, the Lahu people have found a way out of poverty and turned rich. So far, their living standards, the village environment and the surrounding traffic conditions have been improved significantly, greatly promoting the economic development of Lancang County.

\section{B. Carrier of Culture}

Basing on real life of Lahu people and then is discovered, integrated and refined by local people, the show, Lao Dabao Lahu Original Song and Dance whose theme is multi chorus of Lao Dabao village, combines the advantages of Nuofu township's magic drum dance with Mengbin village of Menglang township, A'yong village and Banli village of Donghui township's swing dance. It can, on the one hand, reflect the outstanding folk song and dance of local Lahu people, and on the other hand, cluster Lahu people's abundant cultural resources of Lancang County, so that the excellent traditional culture can be extended. It greatly promotes the inheritance and the protection of ethnic culture, becoming a very important name card in promoting and developing Lahu culture, and laying a solid foundation for Lancang's creating a "Green Golden Triangle" circular tour.

\section{Lubricant of Relationship between Cadres and the Masses}

Lao Dabao, a well-preserved village, is rich in Lahu culture. Giving full play to the characteristics of frontier and the rich 
cultural heritage, the company's predecessor, Lao Dabao art propaganda team uses Lahu song and dance to publicize incorruptible policy and uses Lahu entertainment to carry out anti-corruption activities, creating such anti-corruption song as: NiMaDa, which means perfectly good hearts, CuoDaDie, upright men and People Love Honest Officials. Villagers often gather together on Lao Dabao Lahu playground to perform art programs with ethnic characteristics and art works related to anti-corruption, forming a strong atmosphere of public opinion in which "everyone discuss anti-corruption; everyone evaluate anti-corruption." The literary leader Li Naguo, an ordinary rural woman, becomes a Party representative of the 18th National Congress of the Communist Party of China which plays a positive role in strengthening the construction of grassroots organization, in closing the relationship between government officials and masses, and in promoting the spiritual civilization construction in new socialist countryside.

\section{Stabilizer of National Unity}

After the establishment of Lao Dabao Company, all villagers become its members, so it has nearly 200 actors who are all actively involved into the performance, also arousing the passion and enthusiasm of Dai and Hani nationalities to carry out various culture activities. It, on the one hand, facilitates the understanding, communication and exchange within ethnic and between nationalities, enhances the cohesion and centripetal forces of national culture, and stimulates the unyielding national spirit, on the other hand, effectively curbs the penetration of foreign religious forces, the penetration of national force and the penetration of cultural force, reinforces the construction of rural spiritual civilization, and highlights the charisma and cohesion of national cultural industry. In 2014, Li Naguo, vice chairman of the company, won the honorary title "the Model Individuals of the Sixth National Conference Awarding the Promotion of National Unity and Progress."

\section{E. Driver of Social Stability and Progress}

With healthy ideas and culture, Lao Dabao Company not only enriches the life and promotes the well-being of local people, but also imperceptibly changes their concept, behavior and life. As a result, neighborhood disputes and conflicts are solved, bad behaviors such as gambling, stealing, and fighting have been decreased significantly, and the relationships between villagers are more harmonious than before. What is more, the social mode and folkway have been improved significantly. In addition, the implement of dual management policy, namely the coexistence of village administrative and company management, contributes to the formation of a new rural society management pattern and promotes social progress in directly-entering-socialism ethic group region.

\section{Problems of Lao Dabao Company}

Lao Dabao Company has made some obvious achievements under the attention of local government. But due to the constraint of historical conditions and physical environment of the region, there are also many problems.

\section{A. Old-Fashioned Ideas Restricted by Old Ways of Life}

During the long historic development, villagers help each other, forming the mode of life "sharing with each other", which greatly maintains the harmony and stability within the village. However, deep-rooted traditions severely restrict local people's ability of accepting new things, and egalitarian distribution is widely existed in the company's management policy. First of all, constrained by traditional ideas, the company's management personnel believe the work in the company is purely voluntary and never pay for it. Secondly, the company gets 3,000 yuan for each show, of which $20 \%$ will be set as the company's development funds and the remaining $80 \%$ will be distributed equally to all the workers. Income distribution is based on the number of days they have performed, which means the income of a person who performs a program a day is the same as that of the one who performs four programs a day. It severely damages people's enthusiasm.

\section{B. Being Dependent with Comparatively Low Cultural Staff Quality}

Local Party and government pay great attention to Lao Dabao. Since 2005, by setting up platform, leading the villagers to perform outside, investing stage, the government has spent millions of yuan to support the development of local cultural industry, which indeed, to a great extent, promotes the development of local cultural industry. However, because of backward economy and low education investment in the region, the cultural quality of local people and the labor productivity are low, and market competition consciousness is also weak. Even the company's eight management staffs are restricted to compulsorily elementary school education. Although possessing rich cultural resources, many villages fail to transfer them into cultural products. With a poor subjective initiative and strong dependent thought, some of the villagers have the thoughts of "waiting, relying and taking." Being satisfied with the relatively considerable income brought by the company, they rarely consider the company's future development and plan, which leads to management bottleneck.

\section{Immature Market}

At present, the company is still in its infancy with a few visitors, going through a hard start. What is more, a coordinated process of eating, housing, transportation, buying, and traveling are still limited in some way with a payment imbalance. Though tickets are cheap, there were only 1,158 visitors during the National Day holiday of 2015. With a general income of 36,750 yuan, it had yet not reached the income standard of 50 yuan in Lancang County. At present, the company operates similarly to cooperative mode. Because the performance income only accounts for $30 \%$ of their total household income, some villagers therefore lack group consciousness and lack awareness of time. For example, they will cancel a performance if they have farm work to do. The difficulty in setting up entertainers' management rules and regulations hinders the company's development.

\section{Weakening of Cultural Inheritance}

With the constant effect of modern economies and cultures, as well as different ideological trends, the phenomenon of 
culture homogenization is more and more obvious. The penetration of pop culture and the weakening awareness of historic culture protection in directly-entering-socialism ethnic group region lead to the decrease of the number of people who can sing in or know minority languages. The variation and loss of traditional cultural are accelerating. The culture of directlyentering-socialism ethnic group region is facing the risk of failing to be handed down to future generations.

\section{Countermeasures to Optimize the DEVElOPMENT OF LAO DABAO CULTURAL INDUSTRY}

The above problems seriously hinder the development of Lao Dabao Company, so it is of vital importance to draw up a blueprint for the future development of the company to optimize the allocation of resources, increase the profits, expand the size, and facilitate the cultural industry to function efficiently in social governance.

\section{A. Make greater efforts to cultivate ethnic minority talents}

First of all, improve public awareness of the protection and inheritance of traditional national cultures, actively collecting, compiling, publicizing and excavating the national cultural resources in the guideline of "Form precedes content; preservation precedes excavation." National and folk talents of cultural industry shall be encouraged to conduct bilingual education in the ethnic group areas. Second, make feasible plans of talent cultivation at different levels and in different fields, cultivating or employing managerial and administrative personnel familiar with the knowledge of national and folk cultures and market operation. (Design talents, culture and art direction talents, culture managerial talents, etc.) Last, establish and promote effective talent incentive mechanisms. ${ }^{9}$

\section{B. Develop the modes of marketing}

Develop the modes of marketing, open various sharing paths of cultural resources; make greater efforts in publicity by means of network platform, e-commerce and WeChat platforms, performance accessories, program brochures, music $\mathrm{CD}$, etc, expanding the market of folk cultural performances, folk art commodity as well as the tourist market to set up a tourist resort integrating music, dance, recreation, vacation, interactive experience, agricultural sightseeing, and folk cultural art ware sales.

\section{Give more support}

First, the market cultivation and the gradual promotion of tourist environment call for the industrial and financial support of the government. The government should offer more support by launching the special tour line, improving the infrastructure, developing leading tourist enterprises and encouraging the association between strong enterprises to improve the industrial competitiveness, stimulate the high-end clustering development of the cultural tourism with its own characteristics. Next, open multiple channels for financial cooperation between the government, market, social organizations and individuals, 10 giving more support in industrial and commercial registration, land use, talent introduction and cultivation, information service, and fiscal levy to turn the favorable policies into actual productivity; attract investment to improve the infrastructure of the cultural industry and optimize the current cultural industry system. Finally, pay attention to the supervision and feedback to guide the masses in the right way in case the national culture may get distorted or even lost due to low economic returns.

\section{Explore new mode of management}

Hold on to the development belief, stick to the development path of Lahu culture, keep exploring new management modes in accord both with the market law and the cultural inheritance and protection of directly-entering-socialism ethnic groups. More specifically, first, in terms of social management, further perfect the village regulation, standardize rules of procedure and mobilize all parties to actively participate in the management. Second, in terms of market mechanism, reinforce the training of the management staff, exploring such management modes as "branch and company (cooperative)," "professional managers and company (cooperative)," "agency and company (cooperative)" so that peasants can shake off the burden of life, getting better off by participating in the cultivation and development of cultural industry and really benefiting from the cultural protection and inheritance, ${ }^{12}$ in which case both economic returns and social benefits are achieved.

\section{CONCLUSION}

The paper focuses on Lao Dabao Happy Lahu Performing Arts Company of Yunnan Lancang County to find out obstacles of the cultural industry of Yunnan directly-enteringsocialism ethnic groups in exhibiting social governance functions, which is of vital practical significance for the Party and government to improve the social governance of the directly-entering-socialism ethnic groups.

\section{ACKNOWLEDGEMENTS}

I would like to extend my sincere gratitude to my supervisor, Yan Xiong for his instructive advice and useful suggestions on my article. I am deeply grateful of her help in the completion of this paper. High tribute shall also be paid to the Cultural Industry Office of Lancang County and Lao Dabao Performing Arts Company for the information and support. My sincere appreciation also goes to the conference organizers for providing me the opportunity.

\section{REFERENCES}

[1] Xie Xinsong."On the Social Governance Function of Culture", Ph.D thesis, Yunnan University, 2013,6, P.82.(In Chinese)

[2] Mao Shaoying. "Cultural Governance as the Important Part of Social Governance", Humanistic Lingnan, 2012,8. P.4.(In Chinese)

[3] Han Yong. "Analysis of Rural Social Management Innovation Model from the Perspective of Cultural Governance--An Empirical Study of Guangxi", Administration \& Law, 2013,1,P. 40. (In Chinese)

[4] Long Xiaotao. "Rural Culture Governance", Journal of Chongqing Vocational \& Technical Institute, 2007,9, P.108. (In Chinese)

[5] Zhu Lijia. "On what Dimensions we should Conduct 'Cultural Governance'," Exploration and Free Views, 2014,5, P.9. (In Chinese) 
[6] Li Gang. "An Analysis of Cultural Obstacles in Economic Transformations of Directly-Entering-Socialism Ethnic Group Areas-a Case Study of Yunan",China Collective Economy, 2009,7, P.45. (In Chinese)

[7] Zhou Lianyou. "A Study of Social and Cultural Development of Lancang Directly-Entering-Socialism Ethnic Group Areas", Journal of CPC Yunnan Provincial Committee School, 2005,5, P. 49. (In Chinese)

[8] Propaganda Department of CPC Pu'er Municipal Committee, "A Work Summary of National Culture Protection and Inheritance of Pu'er City". (In Chinese)

[9] $\mathrm{Hu}$ Yi. "The Development of Cultural Industry and the Innovation of Cutural Administrative Establishment, MD thesis, Fujian Normal University", 2002,7, P. 33. (In Chinese)

[10] Xiong Zhengxian. "A Study of Exploitation of National culture Resources and Development of Cultural Industry in WuJiang River Basin", Ph.D dissertation, Southwest University for Nationalities, 2013,5, P.162. (In Chinese) 